\title{
SOME ASPECTS OF THE RESPIRATION OF SIX SPECIES OF FISH FROM UGANDA.
}

\author{
BY G. R. FISH \\ East African Fisheries Research Organization, Finja, Uganda
}

(Recoived 5 September 1955)

The present study is an attempt to correlate ecological data with certain aspects of the respiration of six species of fish typical of local waters. The species of fish examined were:

Lates albertianus Worthington Tilapia esculenta Graham Mormyrus kannume Forsk.
Bagrus docmac Forsk. Clarias mossambicus Peters

Protopterus aethiopicus Heck.

\section{METHODS}

The fish were collected from gillnets or seine nets and usually taken alive to the biological laboratory at Makerere College. Here blood samples were taken which, if not used immediately, were stored below $0^{\circ} \mathrm{C}$. In some cases the fish were bled when they were caught and the blood stored in a vacuum flask containing an ice-salt mixture. The blood was collected from an afferent vessel in the gill arch or from the caudal artery. In the case of Clarias and Protopterus, the blood was taken from the ventricle of the heart. Specimen tubes of $\mathrm{I}$ or $5 \mathrm{ml}$. capacity were cleansed and, before sterilization by dry heat, suitable quantities of Wintrobe's solution (an anticoagulant containing oxalate) were added. The blood from the fish flowed directly into these tubes and, when the required quantity had been collected, the tube was stoppered, shaken vigorously to dissolve the oxalate crystals and stored. Any tubes in which the blood had clotted were discarded. (It was noted that the blood of Tilapia clotted more readily than that of other fish examined. Several specimens often had to be used before a satisfactory sample was obtained.)

The blood was diluted with approximately three parts of distilled water, and the clear supernatant solution of haemoglobin used in a tonometer of the bulb-capillary type (Fox, 1945). Gas mixtures were made up in a manometer which incorporated the gas pipette from the Haldane apparatus and consisted of an inert gas, oxygen and carbon dioxide in carefully measured proportions. The gas, inert from the point of view of respiration, was either nitrogen or hydrogen. This was freed from all traces of oxygen by washing with an alkaline solution of $\mathrm{I}-2-4$ triacetoxybenzene and subsequently by passing through a copper gauze furnace. Air, from which all traces of carbon dioxide were removed by soda-lime, was used as a source of oxygen. Carbon dioxide was obtained from cylinders.

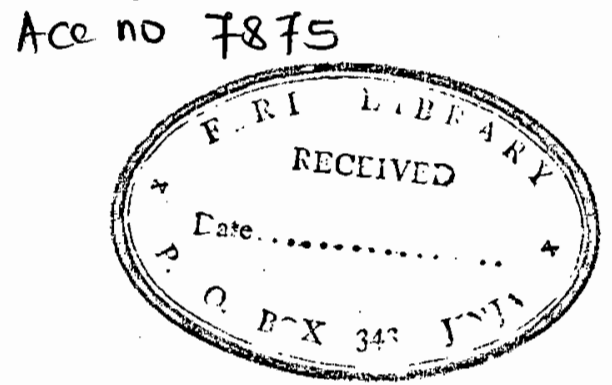


The gas mixture was flushed through the tonometer which was then rotated slowly for $20 \mathrm{~min}$. to allow time for equilibration at room temperature. This varied between 23 and $24^{\circ} \mathrm{C}$. The spectrum of the solution, seen through a Zeiss microspectroscope, was then compared with that of human blood at varying degrees of oxygenation (R. Hill, quoted by Fox, 1945). A 'Crista' comparator was modified so that the spectrum of the standard blood at any degree of oxygenation could be observed in the same field of view as that of the experimental solution of haemoglobin. The haemoglobin content of the fish blood was estimated in a 'Beckman' haemoglobinometer.

Data from five specimens of Tilapia, three of Mormyrus and two of Lates were used in the construction of dissociation curves. The other curves are from measurements using blood from single specimens.

\section{RESULTS \\ Lates albertianus}

Members of this species, which is endemic to Lake Albert, are amongst the largest fresh-water fish. It may be seen from the graphs in Fig. I that the presence of carbon dioxide considerably reduces the capacity of the haemoglobin for combining with oxygen. The haemoglobin is $50 \%$ saturated at a pressure of $17 \mathrm{~mm}$. oxygen, but in the presence of $25 \mathrm{~mm}$. carbon dioxide, the oxygen pressure has to be doubled in order to reach the same saturation figure. It is clear that this fish requires water with a high dissolved oxygen and low carbon dioxide content. A comparison with the dissociation curves obtained from other fish (Figs. 2-6) shows that the haemoglobin in Lates blood has the lowest affinity for oxygen. These data show that, in the absence of carbon dioxide, the haemoglobin cannot be fully saturated unless the lake water in contact with the gills contains at least 5 p.p.m. dissolved oxygen. Such requirements are reflected in its distribution. The waters of Lake Albert are clear, well stirred by the wind and have a very small biological oxygen demand. Dissolved oxygen is likely to be always near saturation point and the carbon dioxide content low. Similarly, other species of this genus are found in waters where the oxygen concentration is unlikely to fall or that of carbon dioxide to rise to toxic levels.

This physiological dependence on well-aerated water may offer an explanation for the occasional heavy mortalities, limited to this species, which are reported from Lake Albert (see also Worthington, 1929).

An extensive mortality occurred in November 1951, and dead Lates were washed ashore in large numbers. Samples were carefully examined, and the available evidence indicated that the most likely cause of death was asphyxiation. The hydrological data below provides a possible explanation.

The main inflow to Lake Albert is the Semliki river which comes from Lake Edward but also has many tributaries from the Ruwenzori and Eturi Forest regions. The examination of water samples, collected at frequent intervals during 1953-4, shows that these tributaries carry water which is relatively cool and rich in reducing 
substances. Data collected by the Hydrological Survey Department (1951) show that, during August 19.5 I, the tributaries supplied an exceptionally high proportion of the total discharge of the Semliki River into the lake. For this short period therefore, the inflowing water, being cooler than the lake water, would tend to flow along the floor of the lake and remain a disparate layer until a sudden storm caused mixing. Gill-breathing fish in these areas would then be adversely affected by the rapid, though probably short-lived, reduction in dissolved oxygen and increase in carbon dioxide.

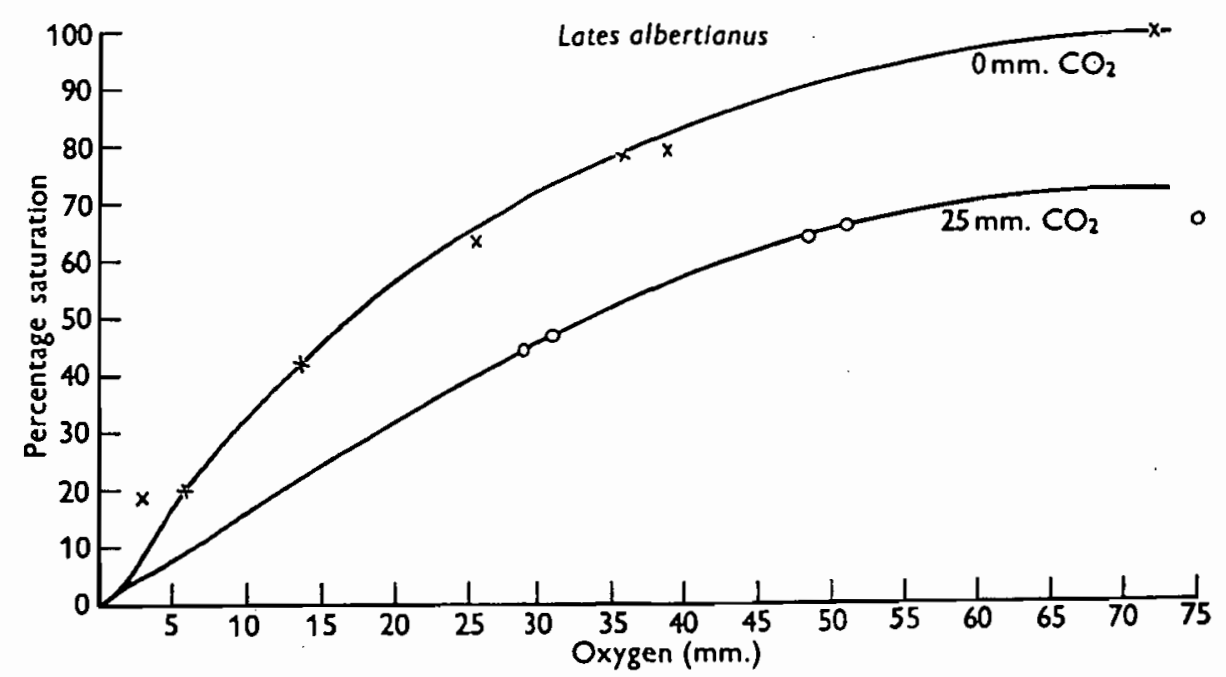

Fig. I. Orygen dissociation curves for hsemoglobin solutions prepared from the blood of Lates albertianus. The average haemoglobin content of the blood used in these estimations was $9 \cdot 1 \mathrm{~g} . / 100 \mathrm{ml}$.

It was remarkable that over $70 \%$ of the dead fish were over $50 \mathrm{lb}$. in weight, many over $200 \mathrm{lb}$. and only about $\mathrm{I} \%$ were less than ro lb. in weight. It seems likely that the larger fish were more closely dependent on optimum conditions of aeration than the smaller specimens.

L. albertianus has been found in the Victoria Nile as far upstream as Fajao and in the Albert Nile as far downstream as Pakwach (Worthington, I929). The spread of this species upstream is clearly limited by the Murchison Falls at Fajao. It seems likely that its spread downstream may be limited by unfavourable conditions of aeration of the water, for recently collected data have shown that, as the Nile flows through the Sudd (a papyrus swamp region extending for about 300 miles), the carbon dioxide concentration in the water rises considerably. The dissolved oxygen content of the water was also found to drop, on occasions, to very low values (Hydrobiological Research Unit, 1954; J. F. Talling, personal communication). 


\section{Tilapia esculenta}

From a commercial point of view, this is the most important fish in Uganda and large numbers are caught annually in Lake Victoria. Tilapia esculenta is found in shallow waters which support a good growth of plankton. Dissolved oxygen concentrations are usually high, but may drop to about $50 \%$ saturation. These coastal waters are frequently bounded by swamps and have a soft muddy bottom. Carbon dioxide in solution is often present, especially after heavy rain when swamp water may be flushed out by inflows into the lake water. The dissociation curve in the

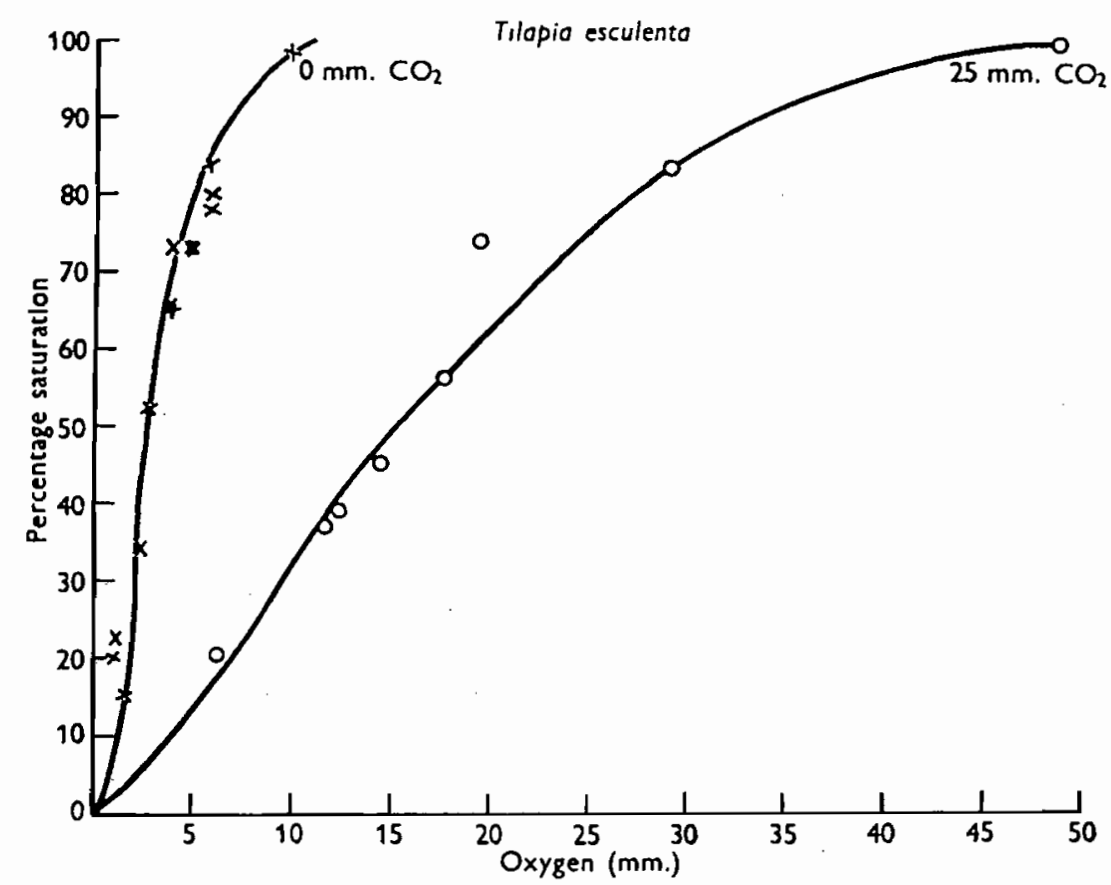

Fig. 2. Oxygen dissociation curves for haemoglobin solutions prepared from the blood of Tilapia esculenta. The average haemoglobin content of the blood used in these estimations was $7.5 \mathrm{~g} . /$ $100 \mathrm{ml}$.

absence of carbon dioxide (Fig. 2) has a steeper slope than that of Lates. The haemoglobin is fully oxygenated at tensions which would barely oxygenate that of Lates to a value of $30 \%$. Tilapia is unlikely, therefore, to suffer from anoxia under conditions which would cause Lates severe respiratory distress.

Occasionally, large mortalities of fish have been reported from Lake Victoria, but details are rarely available (Graham, 1929). A local mortality of fish, however, was reported from Entebbe on 31 July 1953 . The fish affected consisted almost entirely of Tilapia and Haplochromis species. Examination produced no evidence of disease, and local fishermen collected large numbers of dead and dying Tilapia for subsequent sale. A day or so prior to the first reports of this mortality thère was an 
exceptionally strong offshore wind at Entebbe. Such a wind would cause a movement of surface water away from the shore and there would be a corresponding movement inshore of water from the deeper layers in the lake. Temperature records for July show that the density differences between surface and bottom waters in the lake a few miles offshore were small and so relatively little energy would be required to cause a movement of large amplitude of the water strata within the lake. The available data indicate that the cause of this mortality was asphyxiation due to a limited upwelling of poorly aerated water. The difference in slope of the dissociation curves shows that Mormyrus and Bagrus are not as sensitive to poor aeration as Tilapia. This may explain why no members of these genera were found amongst those affected by this mortality.

Samples of the haemoglobin of Tilapia esculenta and of Mormyrus kannume were exposed experimentally to tensions of 50 and $250 \mathrm{~mm}$. $\mathrm{Hg}$ of carbon dioxide. No oxyhaemoglobin could be detected in such solutions at oxygen tensions of up to $30 \mathrm{~mm}$. Hg. It may be significant that the haemoglobin of Tilapia and Mormyrus, after exposure to these tensions of carbon dioxide, behaved abnormally when tested subsequently in oxygen mixtures containing no carbon dioxide. The carbon dioxide gas mixture was flushed out of the tonometer containing the haemoglobin solution by a stream of air, but subsequent observations showed that oxyhaemoglobin, if formed at all, was rapidly broken down again. Powers et al. (1932) found a similar inactivation effect when working on the blood of Cycleptus elongatus (Le Sueur) and of Stizostedion vitreum (Mitchell). This phenomenon may provide an explanation for the observation that, during a mortality, the affected fish are dying even when they have drifted into well-aerated water where others of the same species are suffering no ill-effects.

\section{Mormyrus kannume}

This species occurs throughout the Nile system of lakes and rivers. Its food often consists largely of lake-fly larvae (e.g. Chironomidae) from the bottom deposits. Hydrological records, collected over a number of years, have shown that Lake Victoria is thermally stratified for long periods annually. At these times, dissolved oxygen concentrations in the bottom waters fall to very low values (Fish, unpublished). Mormyrus is therefore exposed to low oxygen tensions whilst foraging very near or in the mud surface. The slope of the dissociation curve (Fig. 3) shows that it is well adapted to withstand such conditions. The haemoglobin concentration in the blood is high, and it is probable that, from the red colour of the muscle tissues, there may also be a high content of myoglobin. It is possible that the relatively high content of haemoglobin and myoglobin in this fish may have an oxygen. storage function and serve to buffer the effect of very adverse conditions of aeration that may be encountered when feeding close to the mud surface. 


\section{Bagrus docmac}

This fish is found throughout the Nile system. Graham (1929) found that, in Lake Victoria, it attained its largest size in the deeper waters but was by no means limited to any particular depth, being caught from 14 to $130 \mathrm{ft}$. The slope of the dissociation curve (Fig. 4) shows that Bagrus can successfully withstand conditions

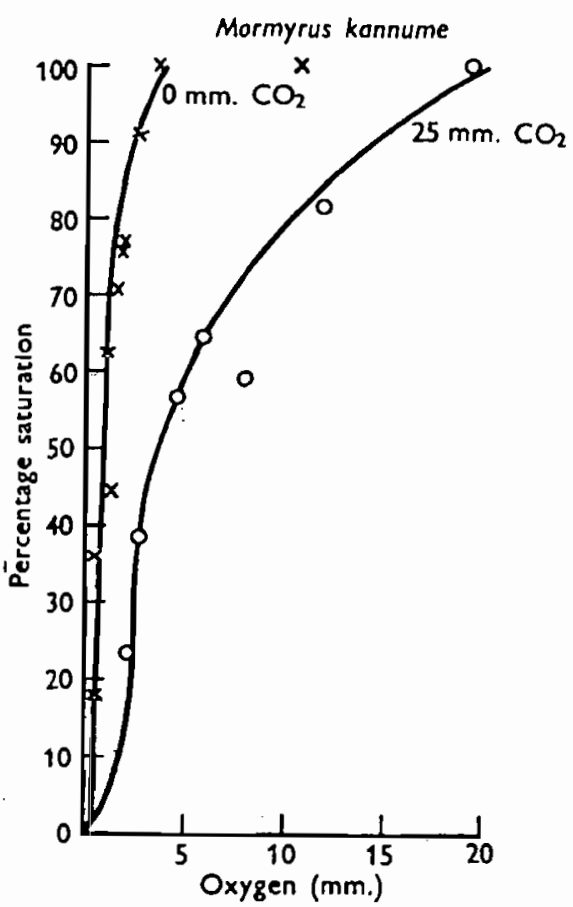

Fig. 3

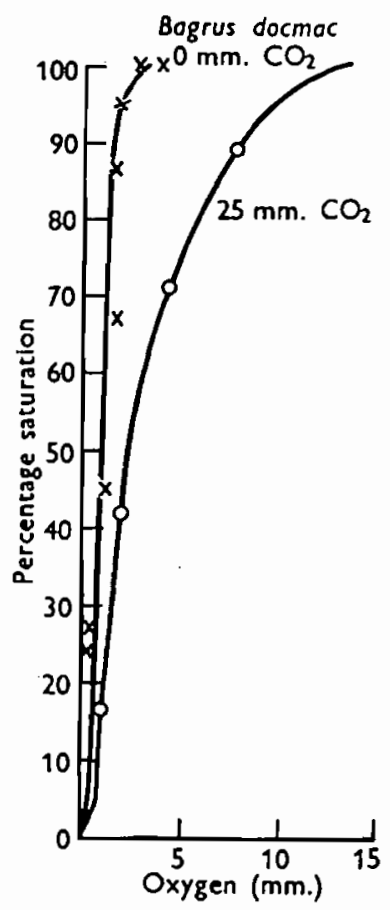

Fig. 4

Fig. 3. Oxygen dissociation curves for haemoglobin solutions prepared from the blood of Mormyrus kanmume. The average haemoglobin content of the blood used in these estimations was I $1 \cdot 7 \mathrm{~g} .1$ $100 \mathrm{ml}$.

Fig. 4. Oxygen dissociation curves for haemoglobin solutions prepared from the blood of Bagrus docmac. The average haemoglobin content of the blood used in these estimations was $6.9 \mathrm{~g} .1$ $100 \mathrm{ml}$.

of low oxygen tension. It is of interest that Graham (r929), recording the stomach contents of 170 specimens which contained food, showed that $17 \%$ of them contained nothing but prawns (Caridina species). A few personal observations have indicated that these may be the only animals within the food range of Bagrus to be found in the deeper waters of Lake Victoria, which are poorly aerated at certain times (see above). 


\section{Clarias mossambicus}

This fish is found in many of the African lakes and swamps and is common in Lake Victoria. It is found at all depths from swamps to over $200 \mathrm{ft}$. of water, and has been seen moving through damp grassland, although it is not possible to say whether these terrestrial excursions are primarily for food or migrations from one locality to another (Welman, 1948). This wide range of habitat is only possible to the fish by virtue of its unusual respiratory mechanism. It depends largely on the

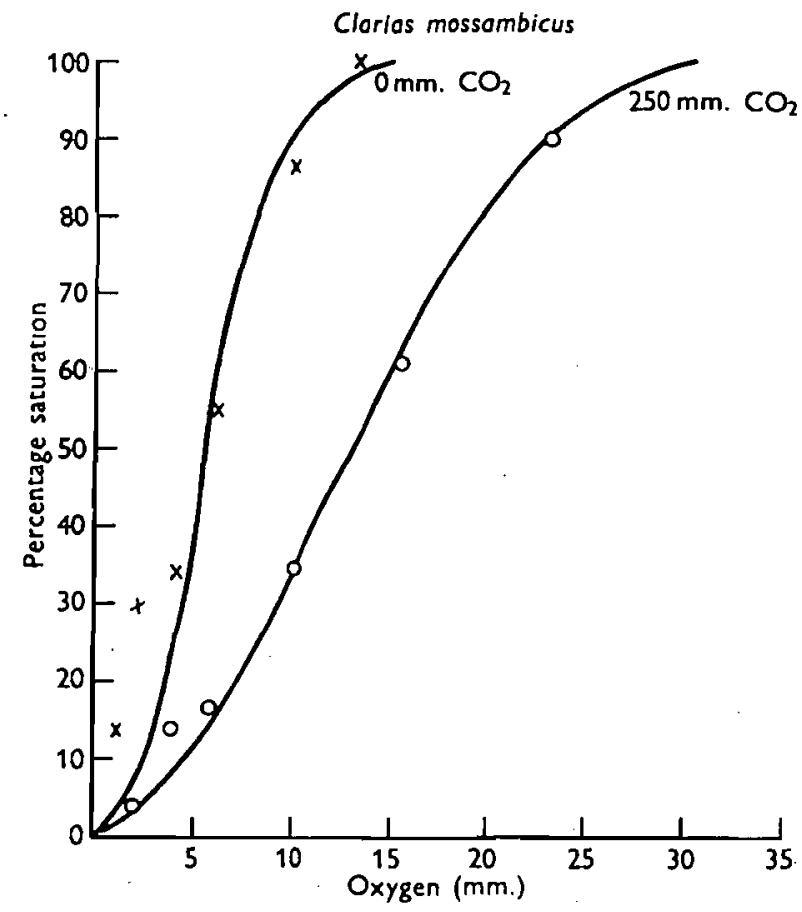

Fig. 5. Oxygen dissociation curves for haemoglobin solutions prepared from the blood of Clarias mossambicus. The average haemoglobin content of the blood used in these estimations was I $3.3 \mathrm{~g} . / 100 \mathrm{ml}$.

oxygen in the air for its respiration and can be asphyxiated if access to air is prevented. The dissociation curve (Fig. 5) in the absence of carbon dioxide is much steeper than that for a fish limited to the open water, such as Lates. Such a curve is advantageous, for Clarias, when leading a purely aquatic life, can only take in a limited volume of air at relatively infrequent intervals.

In comparison with the other fish studied, its blood pigments were found to be remarkably insensitive to carbon dioxide. This property of the haemoglobin is very important in view of the accumulation of carbon dioxide in the air surrounding the supra-branchial organ during the intervals between 'breathing'. This fish is also exposed to high concentrations of carbon dioxide in its swamp habitat. 


\section{Protopterus aethiopicus}

This lungfish is common in the Upper Nile Region and Lake Victoria. It is found in shallow water and swamps and breathing is effected by means of lungs. The dissociation curve (Fig. 6) is similar to that obtained for Clarias in having the same tolerance to very high carbon dioxide tensions. The main difference between the two curves, according to the present data, is that a steeper slope is found in the case of Clarias.

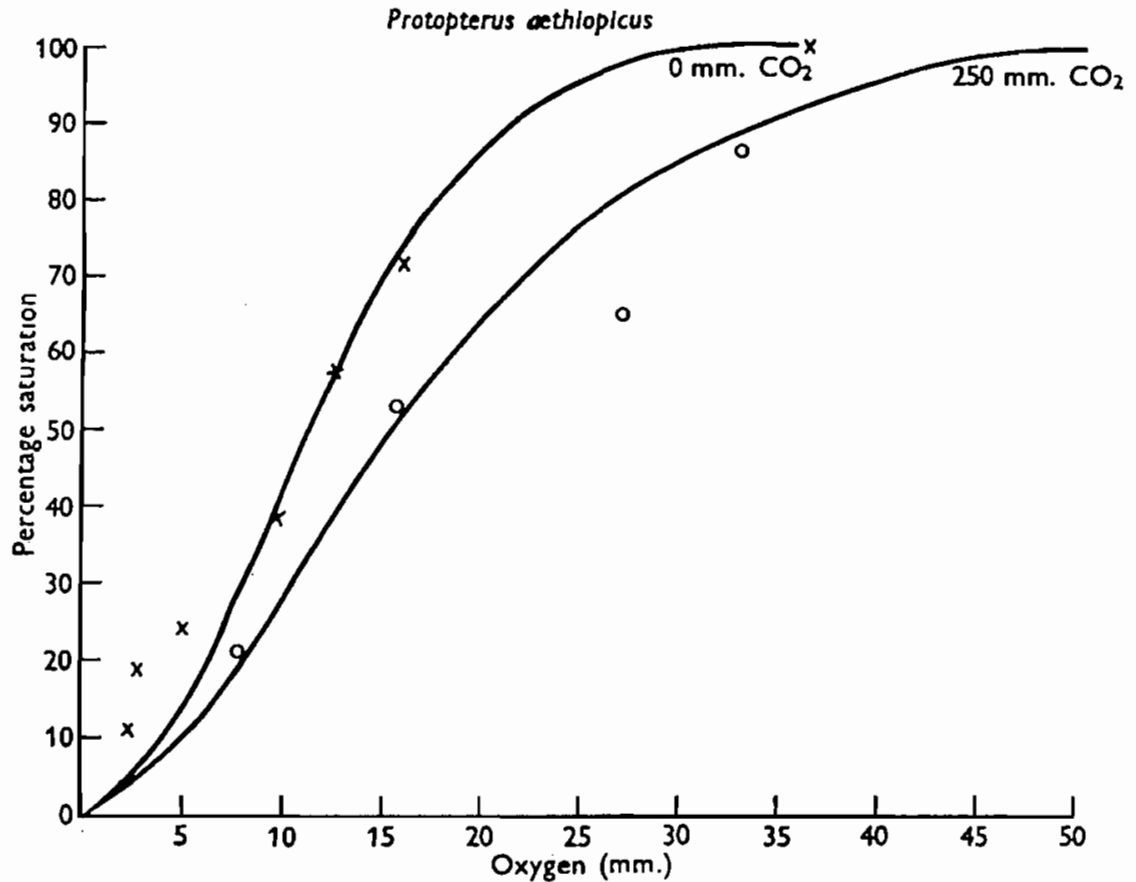

Fig. 6. Oxygen dissociation curves for hsemoglobin solutions prepared from the blood of Protopterus aectiopicus. The average haemoglobin content of the blood used in these estimations was not determined.

\section{DISCUSSION}

It is not unexpected, in view of the variability of aquatic habitats in Uganda, to find large differences in the shape and slope of the dissociation curves for these species of fish. However, Willmer (1934), working with the whole blood of fish in British Guiana, found that the curves, in the absence of carbon dioxide, were similar in all the fish he examined although they came from habitats differing widely in conditions of aeration. The blood from these fish differed widely in response to carbon dioxide, and this response was correlated with habitat. The largest Bohr effect was found in the open-water type of fish, e.g. the paku (Myleus setiger, Mull \& Troschel) and the smallest in the air-breathing swamp fish, e.g. the electric eel (Electrophorus electricus) and the hassa (Hoplosternum littorale Hancock). He found no evidence to 
suggest that the blood of those fish living in swamps was adapted for complete saturation at low oxygen tensions, although such adaptation had been found in carp, pike and eel (Krogh \& Leitch, r9i9).

It must be remembered, however, that these air-breathing fish live in shallow water and are therefore unlikely to be exposed to low oxygen tensions. The fish investigated in this paper are found frequently in deep water and are all lake fish or potentially so. Easy access to the air may not, therefore, always be possible, and their blood may often be exposed to low oxygen tensions. Willmer also noted that fish blood in British Guiana is subjected to tropical temperature $\left(28^{\circ} \mathrm{C}\right.$.) and suggested that, under similar conditions, such blood might easily behave like carp blood if subjected to the lower temperature $\left(15^{\circ} \mathrm{C}\right.$.). The difference between whole blood and haemoglobin solutions was investigated by Root, Irving \& Black (r939), who found that the response to carbon dioxide of whole and haemolysed blood from the same individual fish could be quite different, although the degree of difference varied between species. Bearing these limitations in mind, certain broad conclusions may be drawn relating the dissociation curves for the fish selected here to their ecology.

The haemoglobin from the blood of Lates has a slight affinity for oxygen and shows a considerable Bohr effect in contrast to that of the other species examined. The competence of the haemoglobin as an oxygen collector is low, but as a result, the gas is more readily released in the body. This makes for the efficient cellular metabolism essential for such a fast and powerful predator, but the respiratory surfaces must be bathed in water containing high tensions of dissolved oxygen and negligible carbon dioxide for the haemoglobin to be fully saturated. The haemoglobin of Mormyrus and Bagrus is saturated at low oxygen tensions and therefore takes up oxygen as efficiently in poorly as in well-aerated water. The range of such fish is greatly extended as a result. A high sustained level of activity may not, however, be possible, because the tension of oxygen within the tissues must be comparatively low in order to affect transfer from the haemoglobin. The adverse effect of this oxygen tension in the tissues is often modified in various ways. It is of interest in this connexion to note that, of the fish examined here, those with the steeper curves have the higher haemoglobin contents in the blood.

Carter (1955) has shown that there are large bodies of water in Uganda which are impossible habitats for gill-breathing fish owing to the low dissolved oxygen and the high carbon dioxide concentration present. Certain species of fish are known to survive under such conditions by utilizing the oxygen dissolved in the surface layers of water (G. E. Hutchinson, unpublished material quoted by Allee, Emerson, Park, Park \& Schmidt, I950; Carter \& Beadle, I93 I). Apart from such fish, only those able to utilize the oxygen in the air are found in these poorly aerated waters, namely, Clarias and Protopterus. The very small Bohr effect shown in the dissociation curves of both these fish is necessary for respiration in air-breathing organs which always contain carbon dioxide (Carter, I93I).

Data, collected by American workers on species of Siluroidea, are of interest in this connexion. Prosser, Bishop, Brown, John \& Wulff (I952) note that the 
American catfish has been found to be able to endure tensions of carbon dioxide of the order of $400-500 \mathrm{~mm}$. $\mathrm{Hg}$ for long periods. Black (1940) has also found that the blood of Ameiurus nebulosus (Le Sultar) combines a high affinity for oxygen with a low sensitivity to the presence of carbon dioxide.

\section{SUMMARY}

The oxygen dissociation curves of the haemoglobin of six species of fish from Uganda, and the effect of $25 \mathrm{~mm}$. Hg of carbon dioxide on them are presented graphically. The fish were selected from habitats varying widely in contents of dissolved oxygen and carbon dioxide. The ecology of these species is correlated with differences in the shape and slope of the curve. Records of fish mortalities in Lakes Albert and Victoria are examined in the light of the new data available and suggestions as to the causes are put forward.

This work would not have been possible without the assistance of Prof. L. C. Beadle, Makerere College, Kampala, Uganda. He constructed the apparatus used, made all the estimations of haemoglobin of fish blood, and freely placed his wide knowledge and experience at my disposal. I am grateful, also, to the staft of the Fisheries section of the Game and Fisheries Department of Uganda and that of the East African Research Organization, in particular Mr P. H. Greenwood, for discussion and help in collecting and identifying fish samples. Water samples from the Semliki River were collected by the Department of Hydrological Survey, Uganda.

\section{REFERENCES}

Altre, W. C., Emerson, A. E., PARK, O., PARK, T. \& Schmidt, K. P. (1950). Principles of Antimal Ecology. Philadelphia and London: W. B. Saunders Co.

BlAck, E. C. (1 940). Orygen transport by blood of freshwater fish. Biol. Bull., Woods Hole, 79, 21 5-29.

CARTER, G. S. (1931). Aquatic and aerial respiration in animals. Biol. Rev. 6, 1 .

CARTER, G. S. (1955). The Papyrus swamps of Ugarda. Unpublished.

Carter, G. S. \& Bradle, L. C. (1931). The fauna of the swamps of the Paragusyan Chaco in relation to its environment. II. Respiratory adaptations in the fishes. F. Linn. Soc. (Zool.), 37, 327-68.

FLSH, G. R. (1955). The effect of a seiche on the hydrology of Lake Victoria. Unpublished.

Fox, H. M. (1945). The oxygen aftinities of certain invertebrate haemoglobins. F. Exp. Biol. 2I, 16I-5. Graham, M. (1929). Fishing Survey of Lake Victoria. London: H.M.S.O.

Hydrobiological Resparch Unit (1954). Ann. Rep. University College of Khartoum.

Hydnolocical Survey Department (1951). Arm. Rep. Uganda: Government Printer.

KROGH, A. \& LBITCH, I. (1919). The respiratory function of the blood in fishes. Y. Physiol. 52, 288-300.

LakB Victorls Fisherdes Service. (1953) Amn. Rep. Nairobi: Government Printer.

Powrrs, E. B. et al. (1932). The relation of respiration of fishes to environment. Ecol. Monogr. a, $385-473$.

Prosser, C. L., Bishop, D. W., Brown, St, F. A., John, T. L. \& Wulpp, V. J. (1952). Comparative Animal Physiology. Philadelphis and London: W. B. Saunders \& Co.

Root, R. W., Irvnng, L. \& BLACK, E. C. (1939). The effect of hemolysis upon the combination of oxygen with the blood of some marine fishes. F. Cell. Comp. Physiol. 13, 303-13.

Welman, T. B. (1948). Prelininary Survey of the Freshoater Fisheries of Nigeria. Lagos: Government Printer.

WiLLker, E. N. (1934). Some observations of the respiration of certain tropical freshwater fishes. 7. Exp. Biol. 9, 283-306.

Worthinaton, E. B. (1929). A Survey of the Fisheries of Lakes Kioga and Albert. London: H.M.S.O. 